\title{
Expression of metastasis-associated molecules in non-small cell lung cancer and their prognostic significance
}

\author{
BEOM JIN LIM ${ }^{1,3}$, SUNG SOO JUNG ${ }^{2}$, SONG YI CHOI ${ }^{1}$ and CHOONG SIK LEE ${ }^{1}$ \\ Departments of ${ }^{1}$ Pathology and ${ }^{2}$ Internal Medicine, Chungnam National \\ University College of Medicine, Daejeon 301-721, Korea
}

Received March 30, 2009; Accepted August 27, 2009

DOI: $10.3892 / \mathrm{mmr} \_00000216$

\begin{abstract}
Molecules associated with tumor invasion and metastasis have been actively investigated, but their prognostic significance has been variously reported by investigators. We evaluated the expression of matrix metalloproteinase (MMP)-1, MMP-2, MMP-3, MMP-9, MMP-10, tissue inhibitor of MMPs (TIMP)-1, TIMP-2, $\beta$-catenin, E-cadherin and cyclooxygenase-2 (COX-2) in 43 cases of non-small cell lung cancer (NSCLC). Immunohistochemistry of each marker was performed on tissue microarray paraffin blocks, and the results were determined by a semi-quantitative method using an intensity score (0-3) and percentage score (0-3). The expression scores of each marker were correlated with TNM stage and patient survival data. The expression of MMP-3 and COX-2 was significantly increased in higher stage tumors $(\mathrm{P}<0.001$ and $\mathrm{P}=0.046$, respectively), while a correlation with patient survival length was observed for MMP-1 and COX-2 ( $\mathrm{P}=0.034$ and 0.019 , respectively). All stage I or II cases with increased MMP-1 expression succumbed to NSCLC within 34.1 months. Cases with low expression of both MMP-1 and COX-2 had a significantly longer survival time than cases with high expression of either of the two markers $(\mathrm{P}=0.002)$. These results suggest that MMP-1 and COX-2 are plausible candidate survival markers for NSCLC.
\end{abstract}

\section{Introduction}

Lung cancer remains a leading cause of death worldwide (1). Non-small cell lung carcinoma (NSCLC) comprises approximately $80 \%$ of all lung cancer cases (2). Many therapeutic options including adjuvant or post-operative chemotherapy and

Correspondence to: Dr Choong Sik Lee, Department of Pathology, Chungnam National University College of Medicine, 33 Munwha-ro, Jung-gu, Daejeon 301-721, Korea

E-mail: cslee@cnu.ac.kr

Present address: ${ }^{3}$ Department of Pathology, Yonsei University College of Medicine, Seoul, Korea

Key words: carcinoma, non-small cell lung, matrix metalloproteinases, cyclooxygenase-2, survival analysis surgery have been applied to NSCLC, but with poor results $(3,4)$. Therefore, newly emerging molecular prognostic markers are being meticulously studied by many investigators.

Zhu et al reviewed 462 papers on immunohistochemical prognostic markers for NSCLC published between 1987 and 2005, and summarized the prognostic significance of 50 markers (5). The markers were classified according to their function in tumor growth as molecules that: i) are involved in independent tumor growth [epidermal growth factor receptor (EGFR), HER-2, Ras, Ki-67]; ii) induce resistance to growthinhibitory factors [transforming growth factor- $\beta$ (TGF- $\beta$ ), p21, $\mathrm{Rb}$; iii) induce resistance to apoptotic pathways (p53, Bcl-2, Bax, Caspase 3); iv) induce sustained angiogenesis [vascular endothelial growth factor (VEGF) family members]; and v) are involved in invasion and metastasis $[\beta$-catenin, matrix metalloproteinase (MMP) family members, E-cadherin], among others. Seventeen of these molecules, including p53, Ki-67, EGFR, HER-2 and VEGF-A, have been frequently studied, but their reported prognostic significance as markers has varied (good, poor or none).

MMPs are proteolytic enzymes implicated in many physiological and pathological processes, including embryonic development and morphogenesis. Approximately 28 different MMPs have been identified. The activity of MMPs is controlled by tissue inhibitors of MMPs (TIMPs). To date, four TIMPs (TIMP-1 to TIMP-4) have been identified (6). In healthy lung tissue, fibroblasts express MMP-1, MMP-2 and TIMP-1, and bronchial epithelial cells release MMP-2, MMP-9 and TIMP-1. Type II pneumocytes produce TIMP-2 and MMP-1 $(6,7)$. The expression of MMPs and TIMPs in NSCLC has been studied by several investigators, on the assumption that tumor metastasis is promoted by MMPs and suppressed by TIMPs. Among the MMPs, MMP-2 and MMP-9 (also called gelatinase $\mathrm{A}$ and gelatinase $\mathrm{B}$, respectively) are most often reported to be associated with tumor metastasis.

Based on the report by Zhu et al, in addition to MMPs and TIMPs, we selected certain markers [cyclooxygenase-2 (COX-2), $\beta$-catenin and E-cadherin] that had either not been studied extensively or had produced controversial results, despite their known association with invasion and metastasis. COX-2 is a key enzyme of prostaglandin production and its expression has been observed in both adenocarcinomas and squamous cell carcinomas $(8,9)$. This molecule contributes to tumor metastasis via several mechanisms, including the inhibition of apoptosis and promotion of angiogenesis and 
tumor invasion (10-12). Some authors have suggested that COX-2 has prognostic significance, particularly in earlystage NSCLC (13), but this finding remains controversial (5). E-cadherin exists ubiquitously on epithelial cells, and $\beta$-catenin binds to the intracellular domain of E-cadherin. The E-cadherin-catenin complex is a crucial component of intercellular junctions; thus, altered expression of the complex may promote tumor metastasis and confer a poor prognosis $(14,15)$. However, this assumption has not been verified due to various studies reporting contradictory results regarding the prognostic significance of the E-cadherin-catenin complex (5).

The purpose of this study was to evaluate the statistical significance of molecules that may affect tumor invasion and metastasis, and to identify the most significant prognostic markers among them. The expression of these molecules was evaluated by immunohistochemistry using tissue microarray blocks, and the degree of expression was compared with data on patient survival.

\section{Materials and methods}

Patient selection. Pulmonary adenocarcinoma and squamous cell carcinoma cases diagnosed following surgical lobectomy or pneumonectomy were selected from the surgical records of the Department of Pathology, Chungnam National University Hospital. Cases operated after 2003 were excluded to ensure a follow-up of more than 5-years. Cases without well-preserved paraffin embedded tissue or documented clinical records were also excluded after histologic examination and a review of the chart. A final total of 43 patients ( 37 male, 6 female) were enrolled in the study. The study was approved by the Institutional Review Board of Chungnam National University College of Medicine. Patient characteristics are summarized in Table I.

Tissue microarray construction. Slides of each case were reviewed and, during tissue preparation, a well-preserved tumor area without necrosis or artifacts was marked with an oil pen. Paraffin-embedded tissue was extracted from this area using a tissue microarray kit (3.0 mm, TM0006; Microm, Germany). Each extracted sample was delivered into one of the holes in recipient blocks ( $3.0 \mathrm{~mm}, 30 \mathrm{sp}$ TM0011; Microm). Completely filled recipient blocks were placed in an embedding mold and incubated for $30 \mathrm{~min}$ at $60^{\circ} \mathrm{C}$. After becoming completely transparent, recipient blocks were solidified on a cold plate.

Immunohistochemistry. Each tissue microarray block was serially cut into $4-\mu \mathrm{m}$ sections and stained using an avidinbiotin complex method. Briefly, sections were deparaffinized in xylene and rehydrated with graded alcohol. Antigen retrieval was performed using a microwave oven $(2 \times 5 \mathrm{~min}$ in citrate buffer $\mathrm{pH}$ 6.0). After treatment with $0.3 \%$ hydrogen peroxide, the sections were incubated with primary antibodies as follows: MMP-1, 1:25, overnight at room temperature (RT); MMP-2, 1:50, 30 min at RT; MMP-3, 1:50, 30 min at RT; MMP-9, 1:50, 30 min at RT; MMP-10, 1:50, overnight at RT; TIMP-1, 1:50, $30 \mathrm{~min}$ at RT; TIMP-2, 1:50, $30 \mathrm{~min}$ at RT; COX-2, 1:100, $30 \mathrm{~min}$ at RT; $\beta$-catenin, 1:50, $30 \mathrm{~min}$ at RT; E-cadherin, 1:60, 30 min at RT (all from Thermo Fisher Scientific, CA, USA). After washing with phosphate-buffered saline, biotin-labeled link antibodies and streptavidin-biotin peroxidase were applied
Table I. Summary of patient characteristics.

\begin{tabular}{lc}
\hline Variable & No. of patients \\
\hline Age (years; range 41-77) & $60.3 \pm 9.8$ \\
Sex (male/female) & $37 / 6$ \\
Histologic type & \\
Squamous cell carcinoma & 31 \\
Adenocarcinoma & 12 \\
Stage & \\
I & 11 \\
II & 8 \\
IIIA & 19 \\
IIIB & 3 \\
IV & 2 \\
\hline
\end{tabular}

using the LSAB kit (Dako). Bound peroxidase was detected by diaminobenzidine.

Analysis of immunohistochemical staining. Expression of each primary antibody was evaluated according to a previously described method (16) with modifications. Staining intensity was scored as follows: 0, no staining; 1, faint staining; 2, moderate staining; 3 , strong staining. Moderate staining was determined when the staining intensity was the same as that of the internal control. The staining percentage was scored as follows: 0 , no positive tumor cells; $1,<25 \%$ positive tumor cells; $2,25-50 \%$ positive tumor cells; $3,>50 \%$ positive tumor cells. The intensity score and the percentage score were summed up and the final score was used to divide samples into low-expression (0-4) and high-expression (5-6) groups.

Statistical analysis. The correlation between the final scores of each marker and TNM stage was evaluated by Fisher's exact test. To perform this analysis, markers were re-grouped according to TNM stage into low and high groups (low T, T1-2; high T, T3-4; low N, N0-1; high N, N2-3; low stage, stages I and II; high stage, stages III and IV). Post-operative survival rates were evaluated by the Kaplan-Meier method and statistical significance was evaluated using the log-rank test. Multivariate analysis using the Cox proportional hazards model was performed to identify independent prognostic markers. A P-value $<0.05$ was considered significant.

\section{Results}

Expression pattern of immunohistochemical markers. Fig. 1 shows the intensity and extent of expression in various microarray slides. MMPs, TIMPs and COX-2 exhibited cytoplasmic immunoreactivity, and $\beta$-catenin and E-cadherin showed positive reactions along the cell membrane. Five of 43 cases $(11.6 \%)$ showed nuclear positivity to $\beta$-catenin in addition to membrane staining.

Expression levels and TNM stage. The expression levels of each marker were compared with $\mathrm{T}$ stage, $\mathrm{N}$ stage and overall TNM stage grouping. Distant metastases (M1) were recorded 
A

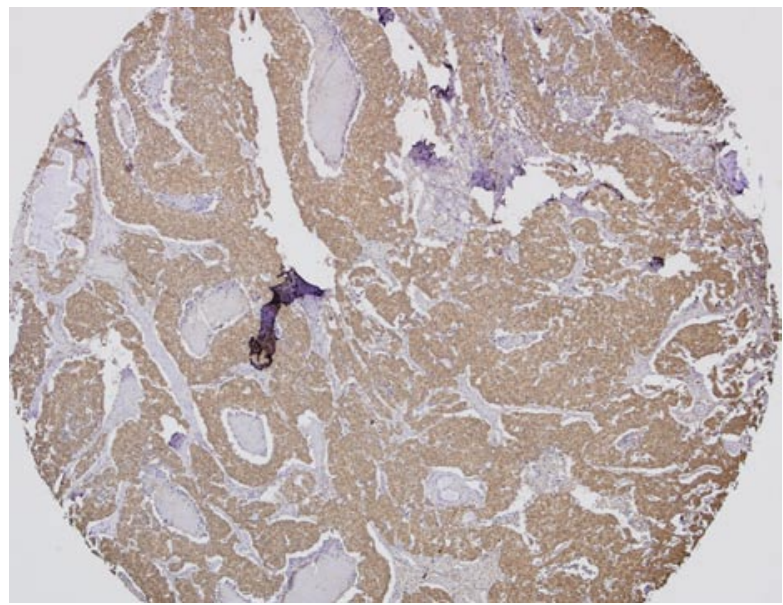

B

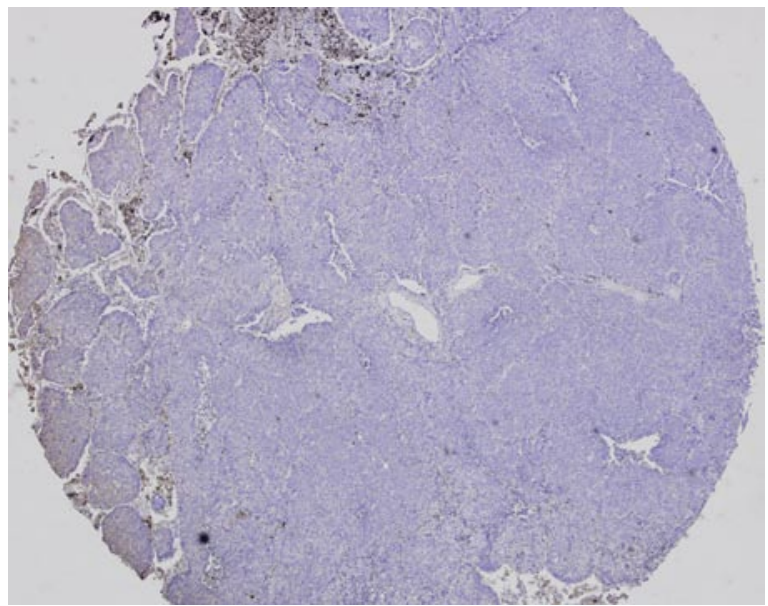

C

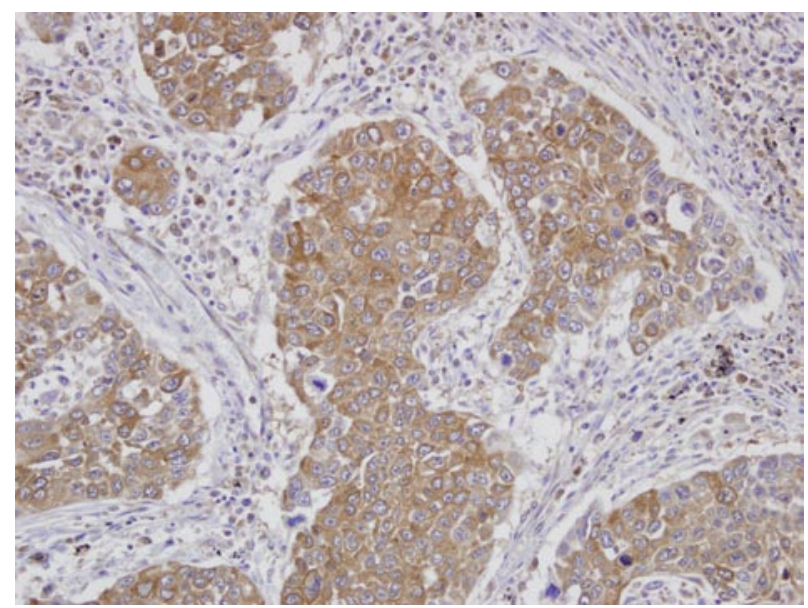

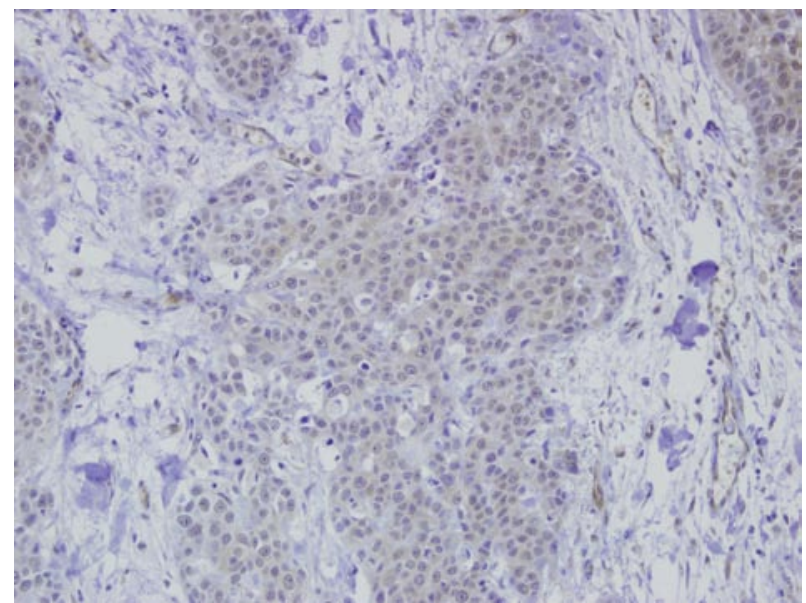

$\mathbf{E}$

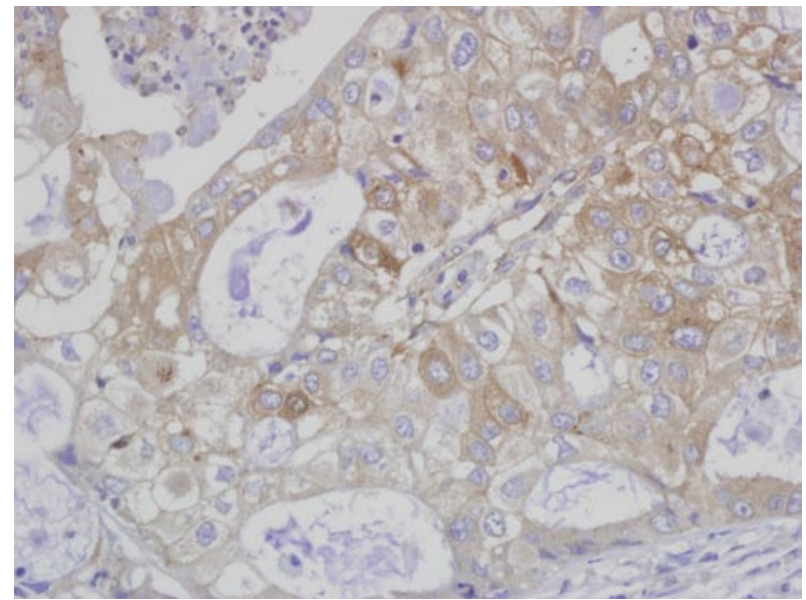

$\mathbf{F}$

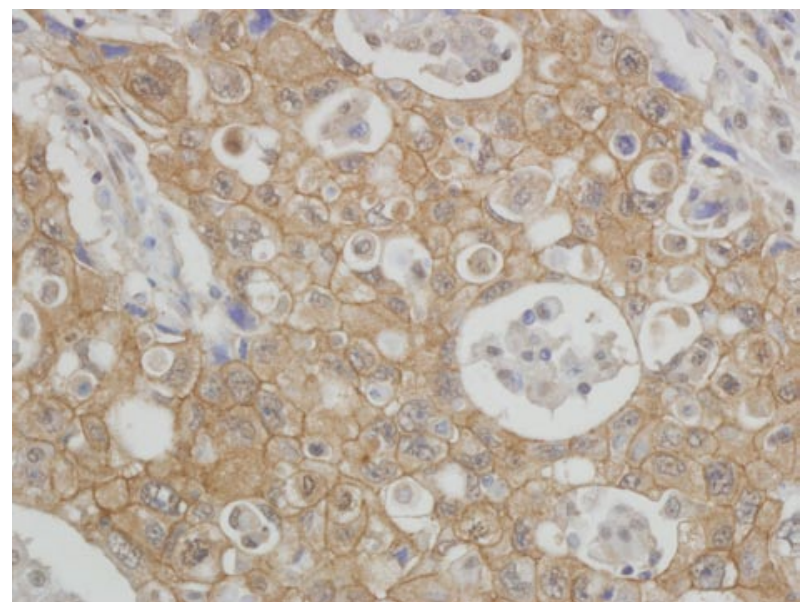

Figure 1. Immunohistochemical stainings of each marker were performed using tissue microarray paraffin blocks. Based on the results, stains were assigned an intensity score (0-3) and percentage score (0-3). A final score was calculated by summing up the intensity and percentage score, and was used to divide samples into low (0-4) and high (5-6) expression groups. (A and C) MMP-1 expression with intensity score 3, percentage score 3. (B) COX-2 expression with intensity score 0 , percentage score 0. (D) MMP-1 expression with intensity score 1. (E and F) Membranous expression of E-cadherin (E) and $\beta$-catenin (F).

in only two cases, therefore comparison with M stage was not performed. None of the markers were correlated with T stage (tumor size). However, certain markers were correlated with $\mathrm{N}$ stage and overall stage grouping. The expression levels of MMP-3, MMP-9, TIMP-1 and COX-2 differed significantly between cases with low and high $\mathrm{N}$ stage $(\mathrm{P}<0.001, \mathrm{P}=0.025$, $\mathrm{P}=0.011$ and $\mathrm{P}=0.020$, respectively). Higher expression levels were correlated with higher stages. MMP-3 and COX-2 were significant markers associated with a high overall stage ( $\mathrm{P}<0.001$ and $\mathrm{P}=0.046$, respectively). MMP-9 and TIMP-1 were also correlated with overall stage, though without statistical significance (Table II).

Expression levels and patient survival. MMPs, TIMPs and COX-2 showed higher survival rates in low expression cases. By contrast, $\beta$-catenin and E-cadherin showed a tendency toward a 
Table II. Relationship between the expression of each marker and tumor stage.

\begin{tabular}{|c|c|c|c|c|c|c|}
\hline & \multicolumn{2}{|c|}{$\mathrm{T}$} & \multicolumn{2}{|c|}{$\mathrm{N}$} & \multicolumn{2}{|c|}{ Stage } \\
\hline & Low & High & Low & High & Low & High \\
\hline \multicolumn{7}{|l|}{ MMP-1 } \\
\hline Low & 28 & 7 & 16 & 4 & 14 & 20 \\
\hline High & 4 & 1 & 19 & 1 & 4 & 1 \\
\hline P-value & \multicolumn{2}{|c|}{1.000} & \multicolumn{2}{|c|}{0.342} & \multicolumn{2}{|c|}{0.162} \\
\hline \multicolumn{7}{|l|}{ MMP-2 } \\
\hline Low & 16 & 4 & 12 & 8 & 11 & 8 \\
\hline High & 18 & 5 & 9 & 14 & 8 & 15 \\
\hline P-value & \multicolumn{2}{|c|}{1.000} & \multicolumn{2}{|c|}{0.227} & \multicolumn{2}{|c|}{0.213} \\
\hline \multicolumn{7}{|l|}{ MMP-3 } \\
\hline Low & 14 & 2 & 14 & 2 & 13 & 2 \\
\hline High & 19 & 6 & 7 & 18 & 6 & 19 \\
\hline P-value & \multicolumn{2}{|c|}{0.448} & \multicolumn{2}{|c|}{$<0.001$} & \multicolumn{2}{|c|}{$<0.001$} \\
\hline \multicolumn{7}{|l|}{ MMP-9 } \\
\hline Low & 21 & 5 & 17 & 9 & 15 & 10 \\
\hline High & 12 & 3 & 4 & 11 & 4 & 11 \\
\hline P-value & \multicolumn{2}{|c|}{1.000} & \multicolumn{2}{|c|}{0.025} & \multicolumn{2}{|c|}{0.055} \\
\hline \multicolumn{7}{|l|}{ MMP-10 } \\
\hline Low & 26 & 5 & 18 & 13 & 16 & 14 \\
\hline High & 6 & 3 & 2 & 7 & 2 & 7 \\
\hline P-value & \multicolumn{2}{|c|}{0.348} & \multicolumn{2}{|c|}{0.127} & \multicolumn{2}{|c|}{0.139} \\
\hline \multicolumn{7}{|l|}{ TIMP-1 } \\
\hline Low & 14 & 3 & 13 & 4 & 11 & 5 \\
\hline High & 19 & 5 & 8 & 16 & 8 & 16 \\
\hline P-value & \multicolumn{2}{|c|}{1.000} & & & & \\
\hline TIMP-2 & & & & & & \\
\hline Low & 28 & 5 & 17 & 16 & 15 & 17 \\
\hline High & 6 & 3 & 4 & 5 & 4 & 5 \\
\hline P-value & & & & & & \\
\hline COX-2 & & & & & & \\
\hline Low & 23 & 5 & 18 & 10 & 16 & 11 \\
\hline High & 10 & 3 & 3 & 10 & 3 & 10 \\
\hline P-value & & & & & & \\
\hline$\beta$-catenin & & & & & & \\
\hline Low & 25 & 9 & 17 & 17 & 15 & 18 \\
\hline High & 9 & 0 & 4 & 5 & 4 & 5 \\
\hline P-value & & & & & & \\
\hline E-cadheri & & & & & & \\
\hline Low & 29 & 8 & 19 & 18 & 17 & 19 \\
\hline High & 5 & 1 & 2 & 4 & 2 & 4 \\
\hline P-value & & & & & & \\
\hline
\end{tabular}

P-values were calculated by Fisher's exact test. Low T, T1-2; high T, T3-4; low N, N0-1; high N, N2-3; low stage, stages I and II; high stage, stages III and IV.

higher survival rate in high-expression cases. However, statistical significance was obtained only with MMP-1 ( $\mathrm{P}=0.034$; Fig. 2A) and COX-2 ( $\mathrm{P}=0.019$; Fig. 2B). Based on multivariate analysis with MMP-1, COX-2 and MMP-9, COX-2 was the most important prognostic factor ( $\mathrm{P}=0.040$; Table III).
In addition, MMP-1 and COX-2 were combined, and were defined as dual marker negative when both the markers showed low expression and as dual marker positive when more than one of these markers showed high expression. When survival analysis using this dual marker was performed, there 
A

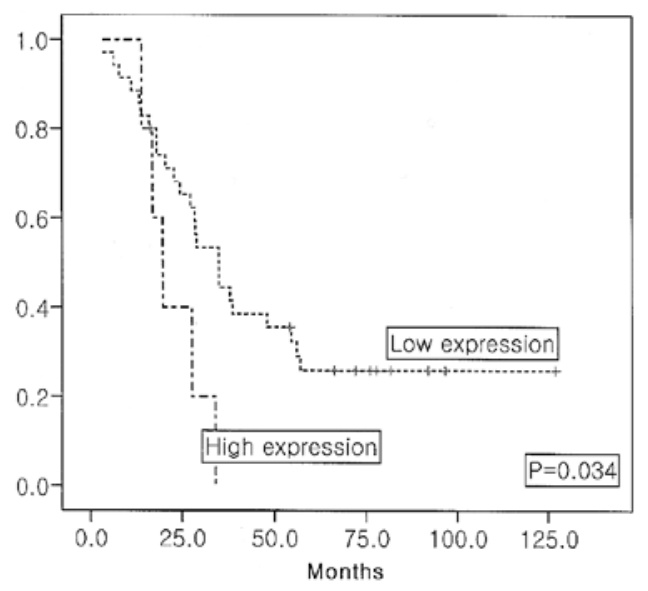

B

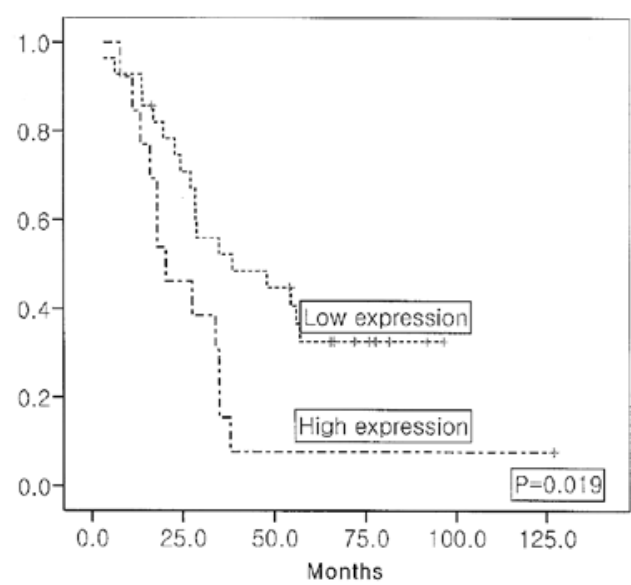

C

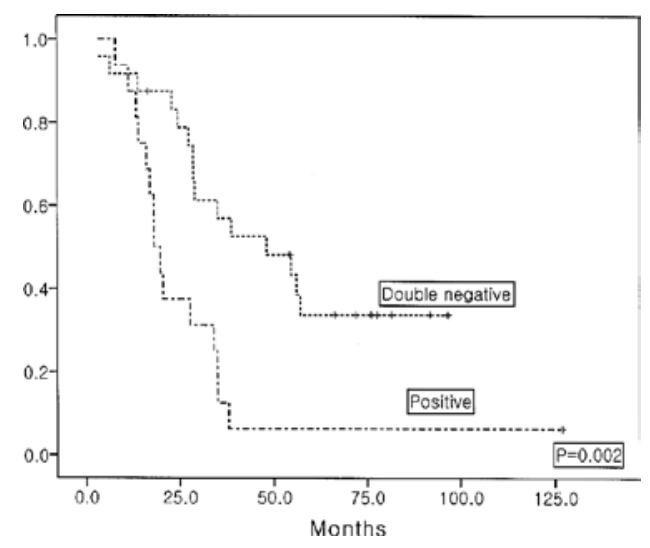

Figure 2. The prognostic significance of each marker was analyzed using the Kaplan-Meier method. Significant correlations were observed with MMP-1 $(\mathrm{P}=0.034 ; \mathrm{A})$ and $\mathrm{COX}-2(\mathrm{P}=0.019 ; \mathrm{B})$. When these two markers were combined, the prognostic significance was intensified $(\mathrm{P}=0.002 ; \mathrm{C})$.

was a significant difference between the dual marker negative and positive group, revealing this dual marker to be the most significant prognostic marker ( $\mathrm{P}=0.002$; Fig. $2 \mathrm{C})$.

\section{Discussion}

The markers included in this study are molecules which mainly contribute to tumor invasion and metastases (one exception is COX-2; as mentioned in the Introduction, various mechanisms have been suggested for this molecule). These molecules are
Table III. Univariate and multivariate analysis of the expression of each marker and patient survival.

\begin{tabular}{lcc}
\hline Markers & $\begin{array}{c}\text { Univariate } \\
\text { analysis }\end{array}$ & $\begin{array}{c}\text { Multivariate } \\
\text { analysis }\end{array}$ \\
\hline MMP-1 & 0.034 & 0.138 \\
MMP-2 & 0.714 & \\
MMP-3 & 0.360 & 0.320 \\
MMP-9 & 0.124 & \\
MMP-10 & 0.289 & \\
TIMP-1 & 0.625 & \\
TIMP-2 & 0.976 & \\
COX-2 & 0.019 & \\
3-catenin & 0.634 & \\
E-cadherin & 0.819 & \\
Dual marker & 0.002 & \\
(MMP-1 + COX-2) & & \\
\hline
\end{tabular}

under active investigation, but to date the reported results have been controversial.

MMPs were among the first markers reported to play a possible role in tumor invasion and the spread of NSCLC, and consequently their inhibitor, TIMP, also received attention. In this study, we evaluated the expression of five MMPs (MMP-1, $-2,-3,-9$ and -10 ) and two TIMPs (TIMP-1 and -2) by immunohistochemistry.

When compared with the TNM staging system, none of the molecules were associated with primary tumor size. However, increased expression of MMP-3 was associated with nodal spread and increased overall stage, and expression of MMP-9 and TIMP-1 showed an association with nodal spread and a possible association with increased overall stage. In spite of these correlations with stage, survival analyses revealed only MMP-1 to have statistical significance.

MMP-3 expression and its prognostic significance have yet to be intensively studied. Thomas et al reported that MMP-3 overexpression evaluated by immunohistochemistry was observed only in stage I NSCLC (17). In contrast, in our study $19(44.2 \%)$ stage III or IV cases exhibited high expression. This difference can be explained by the different counting methods used; we used the combined score of intensity and percentage, while Thomas et al used only the intensity score to evaluate MMP-3 overexpression. Based on the fact that MMP-3 expression did not affect patient survival despite its correlation with nodal spread and overall stage, it can be reasoned that MMP-3 does not directly promote tumor aggressiveness in NSCLC, but rather is a molecule whose expression increases in the late stages of the tumor. MMP-3 was observed to have a protective role in mouse squamous cell carcinoma (18), partially supporting this hypothesis.

It is possible to apply similar interpretations to the expression of MMP-9 and TIMP-1. MMP-9 expression in tumor cells did not affect patient survival in our study, though it was roughly related to tumor progression. However, despite some disagreement (19), the poor prognostic influence of MMP-9 expression has been relatively uniformly reported (20-22). 
Based on the observed survival curve pattern and relatively low P-value (0.124), the possibility of reaching statistical significance is likely to increase with a larger sample number. There are few reports regarding the prognostic significance of TIMP-1 in NSCLC. Gouyer et al reported TIMP-1 expression to be an indicator of worse prognosis, but this was not related to TNM stage (23). In contrast, Simi et al reported that TIMP-1 expression was related not to patients survival, but rather to nodal spread and metastasis (24). Our results were in accord with those of Simi et al. The fact that TIMP-2 was not related to prognosis and disease progression was also in agreement with previous reports $(23,25)$. As its name implies, the basic function of TIMP-1 is inhibiting matrix degradation by MMPs, therefore it is somewhat ironic that TIMP-1 is related with poor prognosis or at least advanced stage disease. This phenomenon can be explained by certain additional functions of TIMP-1 (23), including the promotion of cellular growth $(26,27)$ and the inhibition of apoptosis $(28,29)$.

In the present study, MMP-1 was the only molecule associated with survival among the MMPs and TIMPs. MMP-1 overexpression and its prognostic significance have been more frequently studied in other malignancies (30-32); there are relatively few reports regarding its role in NSCLC. Various authors have reported that lung cancer is associated with a polymorphism in the promoter of MMP-1 (33-35); Sauter et al reported a single nucleotide pleomorphism of MMP-1 to be associated with early-onset lung cancer (36). High expression of MMP-1 was observed in only six cases in our study population; therefore, it is difficult to confirm the prognostic significance of this marker. However, it is notable that all of the six patients died within 14.1-34.1 (median 23.8) months of surgery, though five patients had only stage I or II disease. In other words, MMP-1 overexpression in early-stage NSCLC may be a significant indicator of shorter survival time. This hypothesis should be verified in a larger study population composed of early-stage cases.

The prognostic significance of COX-2 expression in NSCLC has been the subject of heated debate. Certain authors have reported that COX-2 confers a poor prognosis (37-39), while others did not find it to have prognostic significance $(40,41)$ and yet others found it to have a good prognostic influence (21). The present study demonstrated a strong relationship between COX-2 overexpression and shorter patient survival, in addition to the correlation between COX-2 expression and nodal spread and overall stage. The significance of this marker was confirmed in univariate and multivariate analysis. As Yamaguchi et al discussed, these contradictory results might be due to differences in histologic type (adenocarcinoma vs. squamous cell carcinoma) and the degree of differentiation of the tumors included in each study (21). A more controlled study should be conducted in order to settle the controversy.

The predictive value of COX-2 expression became more intensive when combined with MMP-1 expression. Cases with low expression of both these markers showed significantly extended survival time compared to cases with high expression in at least one of the markers. Based on these results, we propose the possibility of a new prognostic marker discriminating cases with a good prognosis in NSCLC.

This study had several limitations in its design. Firstly, cases should have been stratified according to their TNM stage and cell type for a more precise analysis. The failure to obtain statistical significance for some markers, in particular MMP-9, $\beta$-catenin and E-cadherin, was possibly influenced by the small number of cases included. Additionally, It was not possible to evaluate stromal expression of the markers, as each microarray section contained relatively few stroma in comparison with the tumor cells. Despite these weaknesses, the results of the study raise the possibility of new candidate prognostic markers, which should be validated in further investigations.

\section{Acknowledgements}

This study was financially supported by a research grant from Chungnam National University in 2007.

\section{References}

1. Kamangar F, Dores GM and Anderson WF: Patterns of cancer incidence, mortality and prevalence across five continents: defining priorities to reduce cancer disparities in different geographic regions of the world. J Clin Oncol 24: 2137-2150, 2006.

2. Parkin M, Samet J, Tyczynski JE, Shields P, Boffetta P and Caporaso N: Lung cancer epidemiology and etiology. In: Pathology and Genetics of Tumours of the Lung, Pleura, Thymus and Heart. Travis WD, Brambilla E, Müller-Hermelink HK and Harris CC (eds). IARC Press, Lyon, pp12-15, 2004.

3. Alam N, Darling G, Shepherd FA, Mackay JA and Evans WK: Postoperative chemotherapy in nonsmall cell lung cancer: a systematic review. Ann Thorac Surg 81: 1926-1936, 2006.

4. Deslauriers J: Current surgical treatment of non-small cell lung cancer 2001. Eur Respir J Suppl 35: 61-70, 2002.

5. Zhu CQ, Shih W, Ling CH and Tsao MS: Immunohistochemical markers of prognosis in non-small cell lung cancer: a review and proposal for a multiphase approach to marker evaluation. J Clin Pathol 59: 790-800, 2006.

6. Gueders MM, Foidart JM, Noel A and Cataldo DD: Matrix metalloproteinases (MMPs) and tissue inhibitors of MMPs in the respiratory tract: potential implications in asthma and other lung diseases. Eur J Pharmacol 533: 133-144, 2006.

7. Xu J, Benyon RC, Leir SH, Zhang S, Holgate ST and Lackie PM: Matrix metalloproteinase-2 from bronchial epithelial cells induces the proliferation of subepithelial fibroblasts. Clin Exp Allergy 32: 881-888, 2002.

8. Hida T, Yatabe Y, Achiwa H, et al: Increased expression of cyclooxygenase 2 occurs frequently in human lung cancers, specifically in adenocarcinomas. Cancer Res 58: 3761-3764, 1998.

9. Wolff H, Saukkonen K, Anttila S, Karjalainen A, Vainio H and Ristimaki A: Expression of cyclooxygenase-2 in human lung carcinoma. Cancer Res 58: 4997-5001, 1998.

10. Tsujii $\mathrm{M}$ and DuBois RN: Alterations in cellular adhesion and apoptosis in epithelial cells overexpressing prostaglandin endoperoxide synthase 2. Cell 83: 493-501, 1995.

11. Chan TA, Morin PJ, Vogelstein B and Kinzler KW: Mechanisms underlying nonsteroidal antiinflammatory drug-mediated apoptosis. Proc Natl Acad Sci USA 95: 681-686, 1998.

12. Stolina M, Sharma S, Lin Y, et al: Specific inhibition of cyclooxygenase 2 restores antitumor reactivity by altering the balance of IL-10 and IL-12 synthesis. J Immunol 164: 361-370, 2000.

13. Mascaux C, Martin B, Paesmans M, et al: Has Cox-2 a prognostic role in non-small cell lung cancer? A systematic review of the literature with meta-analysis of the survival results. Br J Cancer 95: 139-145, 2006.

14. Bremnes RM, Veve R, Hirsch FR and Franklin WA: The E-cadherin cell-cell adhesion complex and lung cancer invasion, metastasis and prognosis. Lung Cancer 36: 115-124, 2002.

15. Hajra KM and Fearon ER: Cadherin and catenin alterations in human cancer. Genes Chromosomes Cancer 34: 255-268, 2002.

16. Mino N, Takenaka K, Sonobe M, et al: Expression of tissue inhibitor of metalloproteinase-3 (TIMP-3) and its prognostic significance in resected non-small cell lung cancer. J Surg Oncol 95: 250-257, 2007. 
17. Thomas P, Khokha R, Shepherd FA, Feld R and Tsao MS: Differential expression of matrix metalloproteinases and their inhibitors in non-small cell lung cancer. J Pathol 190: 150-156, 2000.

18. McCawley LJ, Crawford HC, King LE Jr, Mudgett J and Matrisian LM: A protective role for matrix metalloproteinase-3 in squamous cell carcinoma. Cancer Res 64: 6965-6972, 2004.

19. Sienel W, Hellers J, Morresi-Hauf A, et al: Prognostic impact of matrix metalloproteinase-9 in operable non-small cell lung cancer. Int J Cancer 103: 647-651, 2003.

20. Cox G, Jones JL and O'Byrne KJ: Matrix metalloproteinase 9 and the epidermal growth factor signal pathway in operable non-small cell lung cancer. Clin Cancer Res 6: 2349-2355, 2000.

21. Yamaguchi NH, Lichtenfels AJ, Demarchi LM, et al: COX-2, MMP-9 and Noguchi classification provide additional prognostic information about adenocarcinoma of the lung. A study of 117 patients from Brazil. Am J Clin Pathol 121: 78-86, 2004.

22. Martins SJ, Takagaki TY, Silva AG, Gallo CP, Silva FB and Capelozzi VL: Prognostic relevance of TTF-1 and MMP-9 expression in advanced lung adenocarcinoma. Lung Cancer 64: 105-109, 2009.

23. Gouyer V, Conti M, Devos P, et al: Tissue inhibitor of metalloproteinase 1 is an independent predictor of prognosis in patients with nonsmall cell lung carcinoma who undergo resection with curative intent. Cancer 103: 1676-1684, 2005.

24. Simi L, Andreani M, Davini F, Janni A, Pazzagli M, Serio M and Orlando C: Simultaneous measurement of MMP9 and TIMP1 mRNA in human non-small cell lung cancers by multiplex real time RT-PCR. Lung Cancer 45: 171-179, 2004.

25. Suemitsu R, Yoshino I, Tomiyasu M, Fukuyama S, Okamoto T and Maehara Y: Serum tissue inhibitors of metalloproteinase-1 and -2 in patients with non-small cell lung cancer. Surg Today 34 896-901, 2004.

26. Bertaux B, Hornebeck W, Eisen AZ and Dubertret L: Growth stimulation of human keratinocytes by tissue inhibitor of metalloproteinases. J Invest Dermatol 97: 679-685, 1991.

27. Hayakawa T, Yamashita K, Tanzawa K, Uchijima E and Iwata K: Growth-promoting activity of tissue inhibitor of metalloproteinases-1 (TIMP-1) for a wide range of cells. A possible new growth factor in serum. FEBS Lett 298: 29-32, 1992.

28. Guedez L, Stetler-Stevenson WG, Wolff L, Wang J, Fukushima P, Mansoor A and Stetler-Stevenson M: In vitro suppression of programmed cell death of B cells by tissue inhibitor of metalloproteinases-1. J Clin Invest 102: 2002-2010, 1998.
29. Li G, Fridman $\mathrm{R}$ and Kim HR: Tissue inhibitor of metalloproteinase-1 inhibits apoptosis of human breast epithelial cells. Cancer Res 59: 6267-6275, 1999.

30. Murray GI, Duncan ME, O'Neil P, Melvin WT and Fothergill JE: Matrix metalloproteinase- 1 is associated with poor prognosis in colorectal cancer. Nat Med 2: 461-462, 1996.

31. Murray GI, Duncan ME, O'Neil P, McKay JA, Melvin WT and Fothergill JE: Matrix metalloproteinase-1 is associated with poor prognosis in oesophageal cancer. J Pathol 185: 256-261, 1998.

32. Nakopoulou L, Giannopoulou I, Gakiopoulou H, Liapis H, Tzonou A and Davaris PS: Matrix metalloproteinase- 1 and -3 in breast cancer: correlation with progesterone receptors and other clinicopathologic features. Hum Pathol 30: 436-442, 1999.

33. Fang S, Jin X, Wang R, et al: Polymorphisms in the MMP1 and MMP3 promoter and non-small cell lung carcinoma in North China. Carcinogenesis 26: 481-486, 2005.

34. Zhu Y, Spitz MR, Lei L, Mills GB and Wu X: A single nucleotide polymorphism in the matrix metalloproteinase-1 promoter enhances lung cancer susceptibility. Cancer Res 61: 7825-7829, 2001.

35. Su L, Zhou W, Park S, Wain JC, Lynch TJ, Liu G and Christiani DC: Matrix metalloproteinase-1 promoter polymorphism and lung cancer risk. Cancer Epidemiol Biomarkers Prev 14: 567-570, 2005.

36. Sauter W, Rosenberger A, Beckmann L, et al: Matrix metalloproteinase 1 (MMP1) is associated with early-onset lung cancer. Cancer Epidemiol Biomarkers Prev 17: 1127-1135, 2008.

37. Achiwa H, Yatabe Y, Hida $\mathrm{T}$, et al: Prognostic significance of elevated cyclooxygenase 2 expression in primary, resected lung adenocarcinomas. Clin Cancer Res 5: 1001-1005, 1999.

38. Khuri FR, Wu H, Lee JJ, et al: Cyclooxygenase-2 overexpression is a marker of poor prognosis in stage I non-small cell lung cancer. Clin Cancer Res 7: 861-867, 2001.

39. Brabender J, Park J, Metzger R, et al: Prognostic significance of cyclooxygenase 2 mRNA expression in non-small cell lung cancer. Ann Surg 235: 440-443, 2002.

40. Hosomi Y, Yokose T, Hirose Y, Nakajima R, Nagai K, Nishiwaki Y and Ochiai A: Increased cyclooxygenase 2 (COX-2) expression occurs frequently in precursor lesions of human adenocarcinoma of the lung. Lung Cancer 30: 73-81, 2000.

41. Marrogi AJ, Travis WD, Welsh JA, et al: Nitric oxide synthase, cyclooxygenase 2 and vascular endothelial growth factor in the angiogenesis of non-small cell lung carcinoma. Clin Cancer Res 6: 4739-4744, 2000. 